\title{
A Research of the Vertical Differentiation of Digital Content Products
}

\section{Basing on numerical simulation analysis}

\author{
Zhenbo Zhang, Lingyi Hu \\ Department of Public Finance, School of Economics \\ Xiamen University \\ Xiamen, China \\ yttl55666@163.com
}

\author{
Bin Wang \\ the State-owned Assets \\ Supervision and Administration Commission \\ Xiamen,China
}

\begin{abstract}
This paper mainly analyze the motivation of enterprises to provide differentiation products, and market result, relevant social welfare effect in digital content products market. First, combing the specific characteristics of digital content products, this paper has developed the "Vertical Differentiation Model of Digital Content Products". And then makes an numerical simulation of this model. We get two primary conclusion:(1)Under the assumption of economic man, digital content market will form vertical differentiation of product quality at last, namely products of different classes will coexist and every enterprise will have relevant stable competitive strategy.(2) The digital content market has a trend that enterprises with high quality products will get higher profit. There are three points of new ideas. (1)introducing specific characteristics of digital content product to the model. (2)loosening previous assumption of rational customer. (3)Introducing non-quality characteristic to the question of quality-choosing.
\end{abstract}

Keywords-digital content product; vertical differentiation; numerical simulations

\section{INTRODUCTION}

Digital content product mainly provides products or service (excluding hardware) that digitalizes pictures, characters, images, sound or other information and integrates them to make these information utilized. This article begins with the vertical differentiation and tries to analyze the motivation, market result and relevant social welfare effect when different enterprises provide different digital content products. Vertical product differentiation indicates that all customers own the same preference order to different groups of products[1]. However,the characteristics of products, typically the quality when taken into consideration, are not the same [2].

This article will develop a vertical differentiation model of digital content product on the basis of the classical researches of vertical differentiation, combined with the concrete characteristics of digital product. It will deduce the mathematical model via numerical simulation.

\section{MATHEMATICAL MODEL}

\section{A. Consumer}

We first describe the characteristics of consumers, the factors that will affect consumption decision and the behavior methods of consumers as followed:
1) The market have $N(N=200)$ consumers.

2) The variables that affect the $i$ th decision of a consumer include:

a) The location $\left(x_{i}, y_{i}\right)$ of a consumer's non-quality preference to the $i$ th product in the two-dimensional space. A consumer achieve more utilities while the location of digital content product is closer to $\left(x_{i}, y_{i}\right)$ in the two-dimensional space. The non-quality preference of $\mathrm{N}$ consumers distribute evenly in a unit circle, which is as shown in the Figure 1.

b) The lowest endurance to some of the inferior products of the $i$ th consumer is $\xi_{i}$. The sum of utilities of every product in the digital content market which belongs to the consumer must be greater than $\xi_{i}$. Otherwise, the $i$ th consumer will abandon his consumption in the digital content market and transfer to other types of leisure or work. The greater $\xi_{i}$ is, the higher demand to digital content products of consumers.

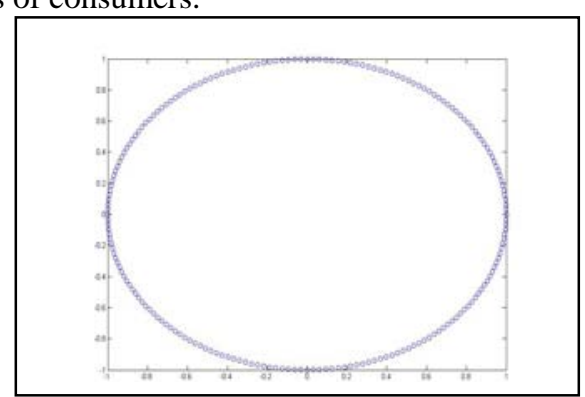

Figure 1. The uniform distribution of non-quality preference of consumers in a unit circle

3) The utility that the $j$ th digital content product belongs to the $i$ th consumer is decided by:

$$
v_{i j}=\left(2-d_{i j}\right) Q_{j}-\xi_{i}
$$

$Q_{j}$ represents the quality of the $j$ th digital content product. And $d_{i j}$ represents the difference value of the $j$ th product between the non-quality characteristic and the preference of a consumer, which is decided by:

$$
d_{i j}=\sqrt{\left(x_{i}-X_{j}\right)^{2}+\left(y_{i}-Y_{j}\right)^{2}}
$$

$\left(X_{i}, Y\right)$ represents the location of the non-quality characteristic of the $j$ th product in the two-dimensional space.

Every consumer makes their own decision for different digital content products accordance with the value of the utility function. When each utility of all digital content products is less than 0 , there will be no consumption. 


\section{B. Enterprise}

Now we will describe the feature of enterprises and its behavior way as followed.

1) The market have $M$ enterprises that produce digital content products.

2) The attributes of the $j$ th enterprise include: the location $\left(X_{j}, Y_{j}\right)$ of the $j$ th enterprise's non-quality characteristic in the two-dimensional space and the quality $Q_{j}$ of digital content product that the $j$ th enterprise produces.

3) As horizonal differentiation is not our main discussion point in this article, we assume $\left(X_{j}, Y_{j}\right)$ is certain. The location value of non-quality characteristic of these enterprises range from $(0,1)$ to $(\cos (1-2 / M) \pi$, $\left.-\sqrt{\left(1-(\cos (1-2 / M) \pi)^{2}\right)}\right)$ in the two-dimensional space, and the next value is the one that locate in the space and has rotated by $2 \pi / \mathrm{Mf}$ the previous value around the circle center. Suppose $M=20$, then non-quality characteristics of these twenty enterprises are distributed in the two-dimensional space as shown in Figure 2.

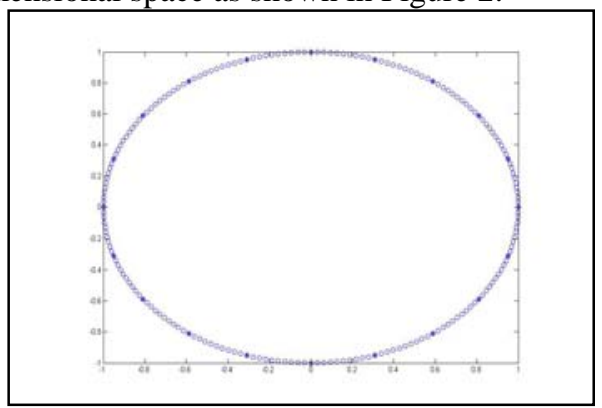

Figure 2. The distribution of non-quality characteristics of twenty enterprises in the two-dimensional space

4) The profit of an enterprise is decided by the function below:

$$
\Pi_{j}=a D_{j}-c Q_{j}
$$

$D_{j}$ represents the consumer scale that the $j$ th enterprise gets by providing digital content products with the quality of $Q_{j} . a(a>0)$ represents conversion rate that transfer consumer scale to profit. $C(c>0)$ represents the parameter of the enterprise cost. Suppose $a$ and $C$ are separately the same for every enterprise.

5) As $\left(X_{j}, Y_{j}\right)$ is certain, the variable of the $j$ th enterprise's decision is the quality $Q_{j}$ of its product. Suppose the $j$ th enterprise choose $Q_{j}$ (we assume the quality of products that the market can possibly provide are

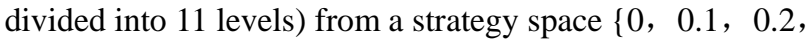
$0.3,0.4,0.5,0.6,0.7,0.8,0.9,1.0\}$. When choosing $Q_{j}$ the enterprise depends mostly on the past experience and it adopts reinforce-learning algorithm to determine the quality of the digital content product that it will provide in each period.

First, we set a transitional vector $K_{j}$ which produces a probability vector $P_{j}$ for the $j$ th enterprise and $P_{j}=K_{j} / \sum K_{j}$. Initially, $K_{j}$ is $(1,1,1,1,1,1$, $1,1,1,1,1)$, which respectively correspond $\{0,0.1$,
$0.2,0.3,0.4,0.5,0.6,0.7,0.8,0.9,1.0\}$ in the strategy space.

The enterprise revises $K_{j}$ according to the following steps:

a) At the beginning, the probability $P_{j}$ for an enterprise to make a decision in all the strategies is $1 / 11$.

b) The enterprise chooses the proper quality level of digital content product it will provide.

c) The enterprise compares its profit for the term and that for the prior period. If earning statements have appeared, this enterprise will adopt the strategy of adding one to the value of the location of $K_{j}$ (namely judging whether this strategy is better than that of the prior period and revising the probability according to the result).

d) If any component of vector $K_{j}$ is 0 , then reset it as 1(this step will ensure the integrity of the strategy).

e) Repeat Step b) to Step d) until the number of the process has reached specified number $L$.

\section{THE NUMERICAL SIMULATION OF THE MODEL AND ANALYSIS OF THE RESULT[3]}

We randomly generate a consumer group and set the number of enterprises as $M=20$, the conversion from the consumer scale to profit $a=0.2$, the parameter of the cost $c=10$ and the iteration number $L=1000$. The result is shown in the Table 1.

TABLE I. $\quad P_{j}$ AFTER N ITERATIONS

\begin{tabular}{|c|c|c|c|c|c|c|}
\hline $\begin{array}{l}\text { Tactics } \\
\text { Enterpxise }\end{array}$ & 0 & 0.1 & 0.2 & 0.3 & 0.4 & 0.5 \\
\hline 1 & 14 & 13 & 1 & 1 & 3 & 143 \\
\hline 2 & 12 & 1 & 1 & 1 & 1 & 139 \\
\hline 3 & 23 & 31 & 6 & 1 & 2 & 114 \\
\hline 4 & 70 & 43 & 14 & 1 & 3 & 18 \\
\hline 5 & 1 & 1 & 3 & 1 & 1 & 131 \\
\hline 6 & 70 & 32 & 6 & 1 & 1 & 45 \\
\hline 7 & 28 & 21 & 1 & 1 & 1 & 151 \\
\hline 8 & 24 & 19 & 3 & 2 & 2 & 104 \\
\hline 9 & 15 & 16 & 2 & 1 & 2 & 146 \\
\hline 10 & 80 & 29 & 11 & 2 & 1 & 28 \\
\hline 11 & 9 & 8 & 3 & 1 & 1 & 135 \\
\hline 12 & 38 & 7 & 4 & 1 & 1 & 130 \\
\hline 13 & 11 & 9 & 2 & 1 & 1 & 152 \\
\hline 14 & 56 & 27 & 5 & 2 & 2 & 86 \\
\hline 15 & 67 & 20 & 5 & 3 & 1 & 92 \\
\hline 16 & 6 & 5 & 1 & 1 & 5 & 112 \\
\hline 17 & 57 & 29 & 30 & 1 & 1 & 27 \\
\hline 18 & 1 & 4 & 2 & 1 & 2 & 117 \\
\hline 19 & 40 & 45 & 4 & 2 & 1 & 82 \\
\hline 20 & 39 & 8 & 1 & 1 & 5 & 119 \\
\hline
\end{tabular}

TAble I. $\quad P_{j}$ After n iterations(Renewal)

\begin{tabular}{|l|r|r|r|r|r|}
\hline \multicolumn{1}{|c|}{ Tactics } & \multicolumn{1}{c|}{$\mathbf{0 . 6}$} & \multicolumn{1}{c|}{$\mathbf{0 . 7}$} & \multicolumn{1}{c|}{$\mathbf{0 . 8}$} & $\mathbf{0 . 9}$ & \multicolumn{1}{c|}{1} \\
\hline 1 & 28 & 9 & 2 & 1 & 1 \\
\hline 2 & 62 & 4 & 4 & 1 & 1 \\
\hline 3 & 2 & 2 & 2 & 2 & 1 \\
\hline 4 & 4 & 1 & 1 & 1 & 2 \\
\hline 5 & 70 & 28 & 11 & 5 & 2 \\
\hline
\end{tabular}




\begin{tabular}{|l|r|r|r|r|r|}
\hline 6 & 3 & 3 & 1 & 1 & 1 \\
\hline 7 & 40 & 8 & 3 & 2 & 1 \\
\hline 8 & 15 & 13 & 2 & 2 & 1 \\
\hline 9 & 32 & 6 & 3 & 1 & 1 \\
\hline 10 & 4 & 3 & 1 & 1 & 1 \\
\hline 11 & 31 & 11 & 3 & 2 & 4 \\
\hline 12 & 17 & 3 & 2 & 1 & 1 \\
\hline 13 & 29 & 4 & 4 & 2 & 2 \\
\hline 14 & 12 & 6 & 1 & 1 & 1 \\
\hline 15 & 5 & 1 & 1 & 1 & 1 \\
\hline 16 & 92 & 25 & 12 & 3 & 2 \\
\hline 17 & 8 & 2 & 1 & 1 & 1 \\
\hline 18 & 87 & 39 & 8 & 2 & 1 \\
\hline 19 & 8 & 1 & 2 & 1 & 1 \\
\hline 20 & 25 & 10 & 1 & 1 & 1 \\
\hline
\end{tabular}

We can conclude from the Table 1 that after 1000 times of iteration probability vector $P$ of every enterprise has changed a lot. Enterprises don't make their decision with the same probability in the strategy space $\{0,0.1,0.2,0.3$, $0.4,0.5,0.6,0.7,0.8,0.9,1.0\}$ any more. They've developed preference to a certain strategy or some. For example, the first enterprise prefers the quality $Q_{1}=0.5$ while the forth enterprise prefers the quality $Q_{4}=0.1$. This indicates that if the digital content providers are aiming at acquiring profit and they make their strategy decision on the basis of past experience, the providers also have different trend to the quality of their products. This will in turn lead to different qualities of products in the digital content market.

We take notes of each profit and the quality expectation of the last 100 periods (each iteration is set as one period). Then we average the results and record them in Table 2 together with every enterprise's last quality expectation.

TABLE II. EXPECTATION OF AVERAGE QUALITY,AVERAGE PROFIT OF LAST 100 PERIODS AND EXPECTATION OF AVERAGE QUALITY OF LAST PERIOD

\begin{tabular}{|l|r|r|r|}
\hline Enterprise & $\begin{array}{c}\text { Average } \\
\text { profit of } \\
\text { last 100 } \\
\text { periods }\end{array}$ & $\begin{array}{c}\text { Expectation of } \\
\text { average quality of } \\
\text { last 100 periods }\end{array}$ & $\begin{array}{c}\text { Expectation of } \\
\text { average quality of } \\
\text { the last periods }\end{array}$ \\
\hline 1 & 0.2752 & 0.4699 & 0.4681 \\
\hline 2 & 0.5743 & 0.5066 & 0.5093 \\
\hline 3 & -0.0762 & 0.371 & 0.3731 \\
\hline 4 & -0.3535 & 0.1494 & 0.1544 \\
\hline 5 & 1.5941 & 0.5647 & 0.5661 \\
\hline 6 & -0.2802 & 0.2067 & 0.2085 \\
\hline 7 & 0.901 & 0.4333 & 0.4409 \\
\hline 8 & 0.0208 & 0.4215 & 0.4193 \\
\hline 9 & 0.2228 & 0.4622 & 0.4613 \\
\hline 10 & -0.2564 & 0.1608 & 0.1696 \\
\hline 11 & 0.3584 & 0.4981 & 0.5005 \\
\hline 12 & 0.0782 & 0.4057 & 0.4049 \\
\hline 13 & 0.3891 & 0.4836 & 0.4848 \\
\hline 14 & -0.2901 & 0.3145 & 0.3126 \\
\hline 15 & 0.2386 & 0.2814 & 0.2878 \\
\hline 16 & 1.4099 & 0.5524 & 0.553 \\
\hline 17 & -0.395 & 0.1957 & 0.5648 \\
\hline 18 & 1.1089 & 0.5612 & 0.3014 \\
\hline 19 & -0.1059 & 0.2984 & 0.4122 \\
\hline 20 & 0.4208 & & \\
\hline & & & \\
\hline
\end{tabular}

According to Table 2, for each enterprise the average quality expectation of last 100 periods is similar to that of the last period. This result indicates that the probability vector $P_{j}(j=1 \ldots 10)$ in Table 1 tends to be stable and can be used to analyze. If we set the average quality expectation of the last 100 periods in Table 2 and the average profit of the last 100 periods of each enterprise separately as the abscissa and ordinate, the result is shown in Figure 3.

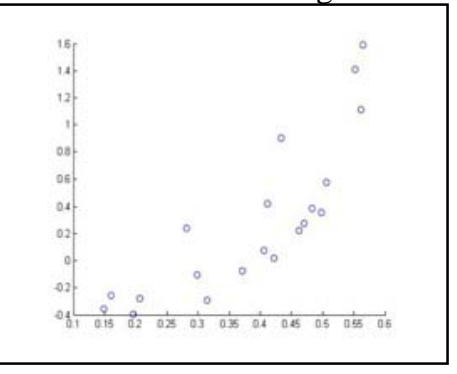

Figure 3. Relationship between the average profit and the average quality of the last 100 periods

As is shown in Figure 3, the enterprise with higher expectation of average quality in last 100 periods will acquire higher profit. This indicates enterprises providing high-quality products tend to acquire higher profits.

To make our conclusion more general, we repeat the simulation for another ten times and make relevant graphs. The results are shown in Figure (a)-(j) as below.

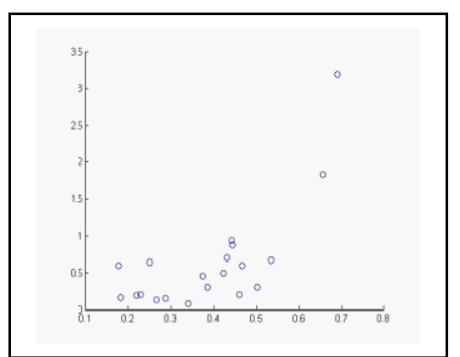

(a)

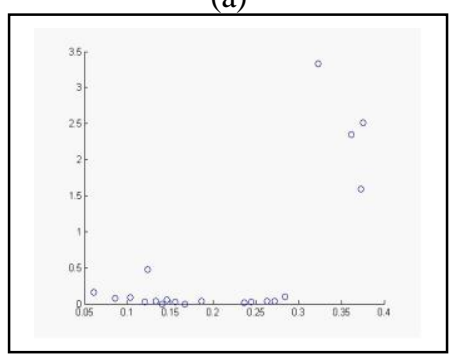

(b) 


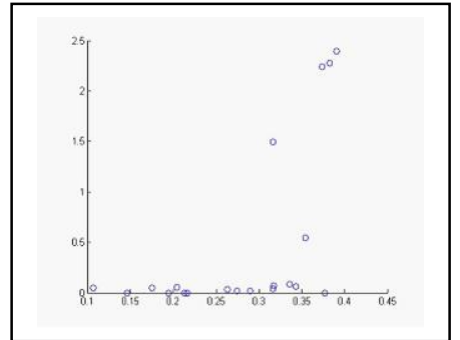

(c)

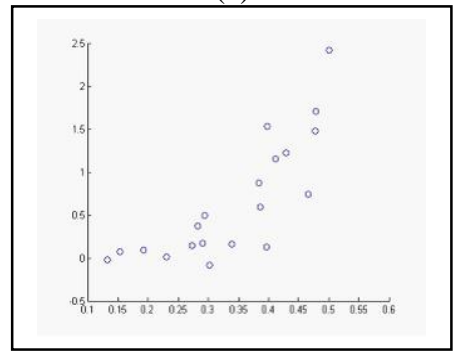

(d)

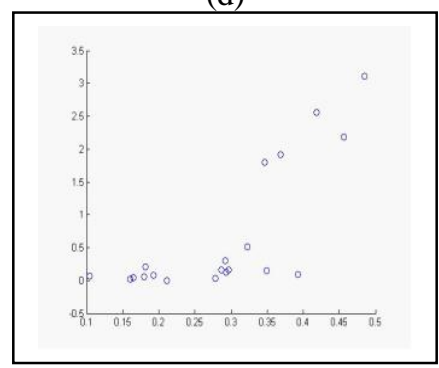

(e)

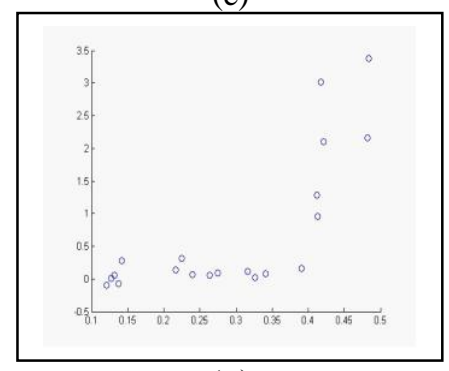

(f)

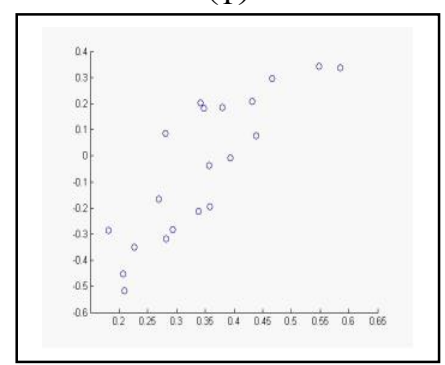

(g)

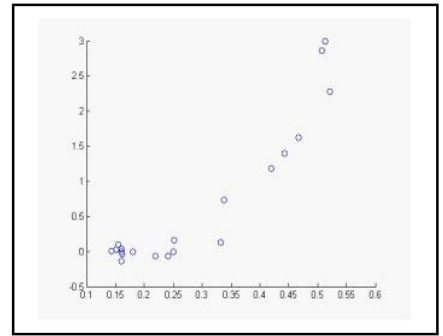

(h)

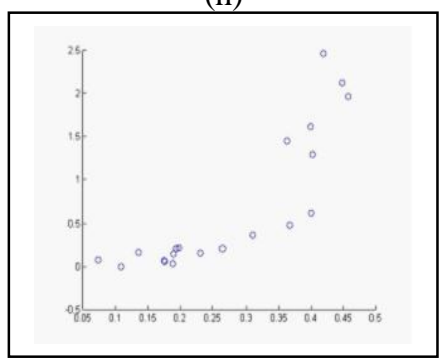

(i)

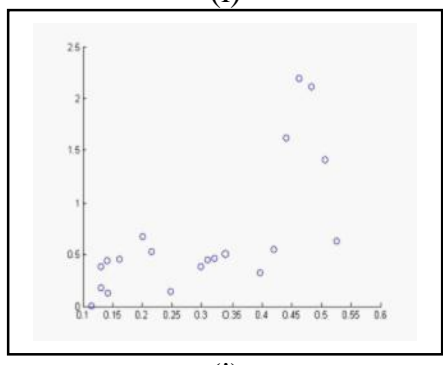

(j)

As is shown in Figure (a)-(j), in every graph the fact that high quality bings high profit is obvious. Actually, this conclusion will not change in some other models.

\section{CONCLUSION}

Through modeling and analyzing the results, we get several conclusions:

By transferring the assumption of rational man to economic man, we find that in digital content market that exists a number of enterprises there will form a vertical differentiation of product quality at last if every enterprise reinforce the process of learning about the past experience. This indicates that different levels of products will coexist and every strategy tends to be stable.

In digital content market, the fact that the higher the quality of one product is, the more profit the enterprise will make is obvious.

\section{REFERENCES}

[1] Ming-hong Zhang. Economics of Network[M]. Beijing: Higher Education Press, 2007

[2] Zhong Liu, ect al. reinforcement learning algorithm [J]. Computer Engineering and Design, 2008(29), 22:5805-5809

[3] Zhenglin Wang, Ming Liu. Profitient in MATLAB7 [M]. Electronic Industry Press, 2006. 